\title{
Towards touch-free spaces: Sensors, software and the automatic production of shared public toilets
}

\author{
Martin Dodge \\ Department of Geography, University of Manchester
}

Rob Kitchin

NIRSA, National University of Ireland, Maynooth

\section{Introduction}

"The public restroom, so unattended by social scientists, is surely a site of analytic riches. ... tensions form around who we are, what we are to share, and with whom we are to share it." (Molotch 2008, 61)

New software-enabled technologies are changing the social and material production of everyday landscapes, and re-figuring the embodied relationships between people and the environment through touch. The places where people are allowed, obliged and forbidden from touching particular technological objects represent a complex and delicately patterned landscape, but one that is negotiated largely in a habitual, non-conscious fashion. Touching with hands is integral to so much technologic activity and control - the pressing of buttons, pulling of handles, flicking switches, twisting selector dials, and so on. Nearly half the working surface area of a laptop used to compose this chapter is a keyboard and touch-pad ergonomically designed for average human hands to engage with software. And yet touch is an overlooked spatial sense and practice in human geography (although see Hetherington 2003, Paterson 2007, Dixon and Straughan 2010). It perhaps then somewhat ironic that in this chapter we are concerned with the reverse situation, as we interrogate the nature of mundane technologies that are designed to work without direct human touch. 
As such, we consider how tools and appliances are being designed and engineered to interact and respond appropriately to people by remotely sensing the presence of human bodies, and offering modes of control that are proximate rather than using physical touch. (There are other non-tactile approaches to computer control such as sound activated controls and speech recognition interfaces, but these are beyond the scope of this discussion.) We want to focus here on electronic/digital technologies, being applied in everyday contexts, that use sensors and software to automatically produce spaces that can react to people (or at a minimum bodily shaped objects) in meaningful ways without direct contact. An increasing number of examples are evident in public buildings and office environments, such as software controlled doors that open automatically when a person approaches, lights and air conditioning that turns itself on when a sensor detects human motion in a room (and turns itself off again when the space becomes empty), and keyless locks that open with the proximity of contact-less radio frequency identification (RFID) cards. Indeed, digital sensors and decision-making software are all about us, monitoring background infrastructures, supervising utility services, regulating material flows, animating objects and environments, and enrolled in solving the myriad tasks of daily living.

The phenomenal growth and influence of digital technologies on everyday activities is due to the emergent and executable properties of software; how it codifies the world into rules, routines, algorithms and data lists and structured databases, and then executes these to do useful work that changes practices and how spaces come into being (Kitchin and Dodge 2011). While software is not sentient and conscious, it can exhibit some of the characteristics of 'being alive' (Thrift and French 2002, 310). This essence of 'being alive' is significant because it means computer code can make things do work in the world in an autonomous fashion - that is, it can receive inputs from its environment and process this information, make decisions and act on them without human oversight or authorisation. When software executes itself in this automatic way it possesses what Mackenzie (2006) terms 'secondary agency'. However, because software is embedded into familiar objects and enclosed systems in often subtle and opaque ways, its presence and power is little considered, and it is typically only noticed when it performs incorrectly or fails (cf. Graham 2009). 
Recently the role of touch to control software has become much more apparent and, one might argue, more intensively tactile. The conventional keyboard/mouse input devices are being rapidly supplanted as many of the most desirable and successful handheld consumer technologies, such as mp3 players, satnavs and especially mobile phones, are operated through sophisticated touch-based screen interfaces that are at once compellingly intimate and intuitive. Touch-screen interfaces are now rapidly becoming routine (on, for example, photocopiers, vending machines, kiosks and parking meters). Software is enrolled to bring space into being in particular ways, and increasingly to change where people touch surfaces, how they touch to control things and make objects perform tasks, and conversely how software mitigates the need for touch in certain instances. Yet the effects of software on tactility of daily activities has not been documented by social scientists (although see Paterson 2007). Research is therefore needed that can account for the tremendous scale and speed of growth of code, including in all kinds of mundane service spaces, and to understand the productive capacity that software has to make the world differently in terms of its materiality, economic relations, social processes and everyday practices (including those most intimately associated with the body, such as toileting).

To begin to explain the nature of this automatic production of touch-free spatiality we concentrate our analysis on shared public toilets, vital but somewhat disregarded spaces of modern life. The focus of the analysis presented here is on 'globalised' Western-style public shared toilets, that are the norm in UK and Ireland. We recognise the reality that much of humanity does not have access to any formal toilet facilities and that the lack of basic sanitation remains a major cause of unnecessary deaths, reflecting and reinforcing the uneven geography of development across the world (cf. George 2008, Jewitt 2011).

Bathrooms outside the home are culturally complex spaces, with multiple ambiguous meanings, providing public spaces for very necessary, private activities, but also spaces necessarily shared. Many people have anxieties around privacy, personal safety and perceived risks of exposure of intimate activities to others and, above all, a sense of vulnerability through enforced sharing of space with strangers (cf. Molotch and Noren 2010). We analyse how some toilet spaces are being reshaped, as technologies are applied that seek to render toileting practices into a sequence of touch-free activities, and attempt to diminish direct handling of the materiality of the bathroom surfaces and 
fixtures. Driven by a range of modernist discourses around hygiene, convenience, and efficiency, it is apparent that many public toilets are now sites of sensors and software that are deployed to react to humans without direct touch: to flush toilets automatically, to dispense soap and water without touching a lever or turning a tap, and sensing the presence of wet hands waiting for drying. However, the logics of software enabled automation able to overcome the fear of contamination and subconscious disgust at direct touching of surfaces shared with strange bodies is frequently nullified because the actual deployment of touch-free sensors is typically incomplete and oftentimes haphazard (most evident in the absence of automatically opening doors). We conclude by considering why the spaces of touch are likely only ever to be partially reconfigurable by software technologies, and what this might mean for the automation of other everyday environments and tactile engagements.

\section{Toilet spaces, toileting practices}

"People care a great deal how they pee and shit. Their strivings for decency confront the facilities available to them as well as the social strictures and hierarchies that order who goes where" (Molotch 2008, 60).

Daily toileting is an elemental physiological function. It is enveloped in a range of cultural practices and complex social meanings. It is enacted in spaces variously configured to conceal these practices and within architectural forms that reflect and reify these meanings. In Western countries toilets are ubiquitous, found in virtually all dwellings and available to occupants of public buildings in the developed world, although their fixtures, materials and layout vary somewhat from place to place (cf. George 2008). For most people in such countries access to specifically designed bathroom spaces, comprising functioning flush WC and sink with clean running water, is seen as essential for convenient and comfortable living.

Toilets are at once mundane, but also an essential service space that everyone uses. Despite its ubiquity, toileting in Western cultures is typically constructed as a most private and solitary function, except for young children. Consequently, the toilet is understood as a taboo space because of the 'uncivilised' practices it seeks to conceal 
from the knowing gaze of others. Understanding toilets as an ambiguous and taboo space revolves around notions of what is clean and what is dirty. Here, the work of anthropologist Mary Douglas (1966) is useful in explaining that dirty and clean are not innate characteristics, but are culturally constructed categories that arise out of processes of social ordering and the production of normative behaviour. Key to the construction of the category of 'dirty' is that it can be defined as 'matter out of place' ("Shoes are not dirty in themselves, but it is dirty to place them on the dining table", Douglas 1966, 36.) 'Matter out of place' varies with cultural context, but is seen as entirely natural to those living within a given culture. While the symbolic boundaries between categories seem strong, they must be continuously maintained, for example with prohibitions, rules and purity rituals that seek to keep matter in the correct place and to punish those who transgress. The shared public toilet is a troubling space because such boundaries are particularly at risk.

The spatiality of being 'in place/out of place' (Cresswell 1996) can be finely grained, for example in the differentiating boundaries between 'clean' and 'dirty' within a bathroom cubicle or even parts of the WC unit. As Bichard et al $(2008,81)$ note: "[t]oileting residue on the toilet seat can be considered dirty as opposed to it being in the toilet bowl; thus a matter of degree can shift our concept of what we consider clean or soiled." Often matter becomes 'out of place' because of the perceived spatial position of an object relative to 'dirty' activities, and also the physical distance to other surfaces that might be harbouring germs. Something that is initially classified as 'clean' may come too close to (but not actually touch) a 'dirty' object or practice and thus itself become 'dirty'. Maintaining 'matter in place' is not just then the avoidance of direct tactile contact, it is about proximity and notions of acceptable distance. The degree of touch, if it occurs, can also matter - just a quick touch of a finger tip on a button might be perceived differently from the requirement to give a firm press of a handle with the palm of the hand.

The work of the categorisation of 'dirt' in determining bodily behavioural and social rules rests to a large degree on the notion of disgust. This powerful emotion compels people to avoid the presence and especially direct contact with sites, objects, individuals, activities that are normally classified as 'dirty'. Contact by sight, smell, sound and especially touch with bodily fluids and human wastes, particularly those of strangers, is widely regarded as particularly disgusting. Excrement, for example, generates an 
affective response of revulsion and fear. As 'matter out place' it needs to be treated specially - quick disposal that avoids contact with bare hands. Indeed, in a hierarchy of human senses it is touch that can evoke disgust most powerfully because 'matter out of place' might possibly enter the body. As such, touching disgusting things is to be avoided at all costs as it implies possible physical contamination through the skin or by ingestion.

Toilets are inherently disgusting places because of unavoidability of physical contact by one's own skin onto surfaces used by others and the fear of contamination from other people's bodily residues (faeces, urine, saliva/spit, vomit, mucous, blood, sweat), both seen and unseen (Greed 2006; Bichard et al 2008; Molotch and Noren 2010). In public toilets this can be accompanied by their associated smells, commingling with the background chemical cleaning products, and the sounds of others performing: groans, farts, sputters and plops, and satisfied sighs. One might also on occasion literally feel the presence others: "[w]e all know ... the sensation of a toilet seat still warm from a prior body, the stranger sensed in so disquieting a way" (Molotch 2008, 61). Affective responses to the toilet space are heightened by disturbances to the general sense of orderliness and maintenance which can be evoked by unidentifiable stains on the cubicle walls, grimy looking smears on surfaces, scratches, cracked tiles, vandalism in the form of graffiti, burn marks, and broken fixtures, the presence of litter and loose toilet paper ('matter out of place'). The extent of these signifiers, in aggregate, can mark a public toilet as uncared for and thus unclean.

The toilet is then a deeply problematic site, and doubly so when a public one. It is an arena which in 'matter' from human bodies routinely becomes 'out of place'. Western toilets, with flush WCs, are designed to engender control of such 'matter out of place' as far as possible and to remove it quickly and hygienically. The design and use of technological systems for waste control are also accompanied by particular toilet cleaning regimes to disinfect surfaces, along with the necessity to clear occasional blockages and maintain plumbing in working order. Touch-free technologies, as the latest iteration in bathroom design, resonate with the scalar spatiality of disgust and seek to provide automated mechanisms to maintain bodily distance from 'matter out of place'. Although users still might see and smell 'matter out of place', and thus have an awareness of sources of disgust, they are protected against physical contact with it. 
Touch-free technologies are, therefore, fundamentally about disgust control, although this is usually dressed up in more delicate language of hygiene and efficiency (see discussion below).

\section{Toilets technologies}

“... the chances of pathogen transmission are very high even in toilets that may appear to look clean, as every door handle (especially the last one out to the street), tap, lever, flush, lock, bar of soap, toilet roll holder, and turnstile, is a potential germ carrier" (Greed 2006, 128)

Even a basic bathroom, in the modern western context, is a highly technological space, reliant on a raft of scientific and engineering developments to make it function as required $^{\mathrm{i}}$. Toilets are also tangible contact points between human bodies and the sewer network, a vital but hidden infrastructure to channel, control and remove 'matter out of place'. Toilet technologies need to be efficient in performing hydraulic tasks (while water flows easily with gravity, it is heavy to move and difficult to fully contain) and should be reliable. Many ingenious mechanical solutions have been engineered to safely regulate the supply of water - siphonic cisterns, self activating cut-off valves, overflow outlets - and, in some senses, to automate aspects of toilet space and thereby compensate for human oversight and lassitude. Safety is also a particular issue in terms of heating water and carefully separating water from the electrical equipment. (This might partly account for relative lack of integration of electrical appliances and electronic technologies into bathrooms, particularly in comparison to other domestic and work spaces.) In many respects, the technicity of modern plumbing and bathroom fixtures only becomes apparent in failure: a blocked waste pipe reveals just how quickly the convenient sense of a normal flush toilet can unravel (cf. Graham 2009).

A range of mechanisation, along with specially designed hygienic materials, are deployed in toilets to increase the psychological detachment from the physiological acts defecation and thereby to counteract the fears of contamination, and they also support ritualistic aspects of cleanliness such as hand washing. Examples include the WC u-bend that holds a reservoir of water to block sewer smells, a powerful flush that whisks away waste, 
sinks with running water on-demand, the wipe-clean white ceramic tiles that can be easily inspected for (visible) dirt. Although technological advances in the name of cleanliness do not necessarily perform unproblematically; as Greed $(2006,129)$ comments: "[o]stensibly, hygienic equipment, such as electric hand-driers (often imagined to be safer than towels) may blow germs back into the atmosphere." While surfaces may appear to be clean, there could lurk hidden hygiene problems in toilets, including recent fears of newly resistant 'superbugs', evolved, in part, as a result of antibacterial cleaning regimes.

Evolving technological solutions have sought to render shared public toilets ever more automated in recent decades. Automation is presented as advantageous to the users of the toilets and to those who have responsibility for maintaining and managing them. Our primary concern here is with development of digital technologies that are designed to negate the need to touch toilet fixtures. Such automation works, we would argue, because it makes toilet technologies progressively more distanced and opaque in use. For example, operation of the standard flush WC has evolved from the once common pull chord to release water from an overhead cistern, to a push lever on the side of the WC cistern, and now widespread pressing of duo-flush buttons on top of the cistern offering choice of big and small flows. The latest trend is touch-free flush controlled by waving over a strategically positioned passive infrared (PIR) sensor that activates a control circuit to release a calculated volume of water from a hidden cistern (Figures 1 and 2), and the next development is no direct human operation at all - software activates the flush when a sensor detects the user has finished as their body vacates the WC seat. This automation translates into diminishing kinaesthetic skills needed to operate the toilet WC, and reduces the duration/intensity of hand touch of control surfaces (Table 1). It also has fewer external moving parts to be physically manipulated and potentially vandalised. Activities that are harder to automate with touch-free technologies are to do with access in terms of door opening and locking / unlocking, which means the coping practices that Bichard et al $(2008,80)$ describe will likely continue:

“...users described how locking the toilet cubicle door could only be done with a handful of toilet paper acting as a barrier between the hand and door lock. This behaviour was considered most beneficial before toileting, to prevent unknown and unseen dirt contaminating the more personal areas of the body." 


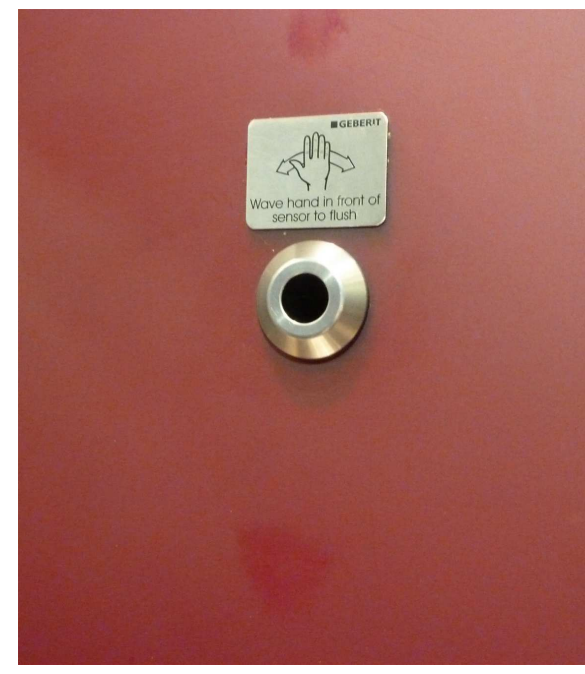

Figure 1. A typical 'magic eye' sensor in a WC cubicle in a shared public toilet in the UK. The physical form of the sensor does not follow function hence the presence of the small explanatory sign indicating usage in text and image. The fact that signage is deemed necessary is indicative that these kinds of touch-free sensors are not yet sufficiently common and standardised to be transparent; it is not be necessary to sign the usage of a WC push handle flush. (Source: author photograph.)
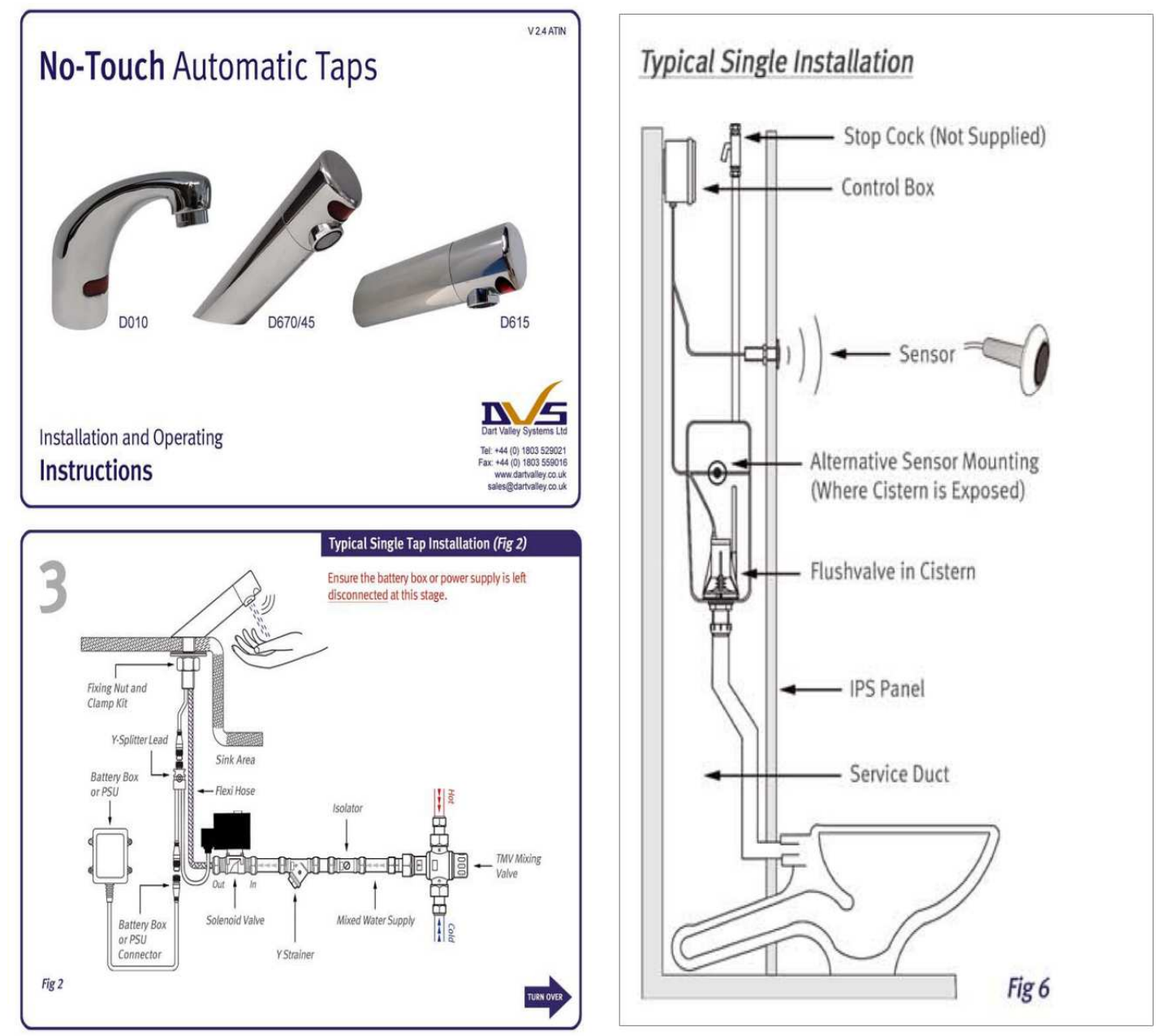

Figure 2. Schematics for typical installation of 'no touch' automatic taps (left hand images) and wave activated WC flush (right hand image). (Source: Manufacturers pdf brochure, Dart Valley Systems Ltd, <www.dartvalley.co.uk>, 2010.) 
In addition to the WC unit, the most common forms of touch-free bathroom mediation are automatic lighting, taps, hand dryers, urinal flushing, and dispensing of consumables such as toilet paper, soap and towels. Table 2 provides a summary of the technologies that are in use in at least some shared public toilets in UK/Ireland. As discussed below very few, if any, shared public toilets have the full spectrum of automation technology installed.

Table 1. The evolving WC technologies in relation to changing levels of direct hand touch of control necessary to complete the task.

\begin{tabular}{ll}
\hline Flushing a WC toilet & Intensity of tactile contact \\
\hline Manual sluicing away of waste & Multiple potential hand touches, collecting, aiming and \\
& pouring water \\
Release chain to overhead cistern & Firm grip with whole hand and strong yank \\
Lever release & Press with fingers or palm of hand \\
Dual flush button & Light ('fingertip') touch activation \\
Hand wave PIR sensor & No direct touch, active wave of hand \\
Occupant / body movement sensor & $\begin{array}{l}\text { Passive 'walk away' activation, no conscious interaction } \\
\text { to flush or tactile contact }\end{array}$ \\
\hline
\end{tabular}

Crucial to the automation of toileting practices to reduce the sense of disgust are digital sensor technologies. Sensors can operate by detecting changed environmental conditions using different parts of the electromagnetic spectrum including light, sound, heat, as well as the presence of physical material, such as smoke, water or human bodies. Such detection has been used routinely in public space, including bathrooms, for many years in alarm systems for fire, flooding and security. Typically they work in a passive way, set up to monitor space and remain inert as long as conditions remain 'normal', only triggering a response if a predetermined threshold level is breached (e.g., exceeding a particulate level in the atmosphere sets off the smoke alarm). Having multiple sensors and processing software means location indications can be generated. Sensors are most obvious through separate detector boxes mounted on visible surfaces, but the detector circuits can also be integral to the equipment to monitor its operation (e.g., door opening) and detecting an abnormal operation or failure (e.g., measured water flow indicates the failure of a valve). 
Technologies have also offered progressively more control over the toilet space for those responsible for their daily cleaning and general management. For example, hygiene control for urinals, with flushing performed as purely mechanical cycle (cistern fills then flushes, and repeats) systems or via direct activation from the user, have been augmented by electrical controls that offered sequences of flushing and remote activation of 'super flush' for cleaning, for example, and also facilitates removal of direct user activation (and thereby reducing external fixtures for misuse/vandalism). Updating to electronic systems for urinal flushing meant managers could select different timed flush sequences and also monitor for faults. The addition of sophisticated digital controls with software interface offers programmable settings and a choice of responses to sensor inputs, as well as logging of performance for later analysis. This is evidence of the shift of local to remote control through sensors and software, and accordingly Braverman $(2010,15)$ reads this change with Bruno Latour's notion of 'centres of calculation', arguing that:

" $[\mathrm{u}]$ nlike the flushometer, which embodies a gaze that is only present in the space of the washroom itself, the central computer manages the washroom from a central location located elsewhere. Hence, the flushing device is not only programmed initially by the manufacturer but through continuous programming and reprogramming."

The ultimate degree of automation for management control is in a sense realised by the APT, typically free-standing single user WC toilet in the street that requires payment to use. Usage is time limited and they are fully cleaned automatically after each cycle (cf. Braverman 2010).

\section{Promotional discourses for automated toilet technologies}

An examination of the marketing literature of UK toilet technology manufacturers reveals that a wide range of narratives are used to promote touch-free bathrooms that encompass and extend beyond ideas of disgust and 'matter out of place'. For many manufacturers the addition of sensors and software is a significant means of 'adding value' to existing product ranges, to facilitate further sales and/or more profitable pricing structures. Six discourses predominate:

- perceived hygiene and potentially real health benefits

- additional convenience and comfort

- being 'modern' 
- easy installation and greater reliability of operation

- enhanced control and configurability

- promise of saving and efficiencies

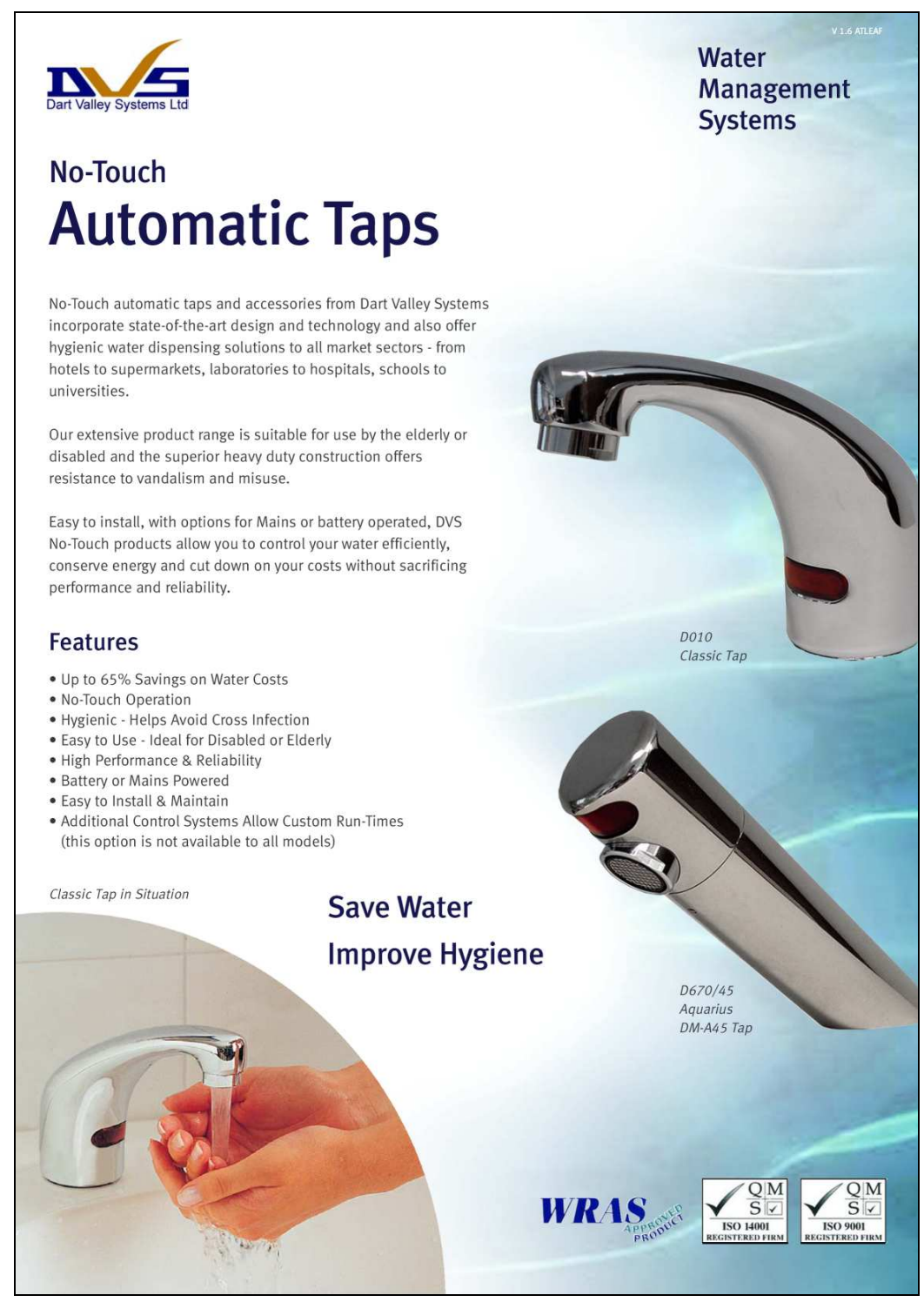

Figure 3. A sample page of a sales brochure promoting the virtues of automatic taps for shared public toilets. The layout, typography and ordering of items in bulletinpoint list is revealing of the prioritisation of discourses. (Source: Dart Valley Systems Ltd, <www.dartvalley.co.uk>, 2010.)

The operationalisation of these discourses is well illustrated by the promotional brochure for typical automatic taps (Figure 3). This brochure encapsulates several of the master narratives around such toilet technologies when it states: "DVS No-Touch products allow 
you to control your water efficiently, conserve energy and cut down on your costs without sacrificing performance and reliability". Here is the classic 'win-win' technology sales pitch: to be more efficient, but still provide the same service. The stress is also on the control afforded, along with claims of reliability. The key visual element in the advert is the automatic taps in operation washing (already clean) hands, accompanied by the claim "Save Water - Improve Hygiene", linking two distinct discourses underlying toilet automation to mutually reinforce each other.

The appeal to saving resources through efficiency is key, with claims that automation offered by sensors and software can deliver significant reductions in water usage: "Up to $65 \%$ savings on water costs" (Figure 3). Automated taps programmed to supply an 'optimal' burst of water only when hands are directly under the faucet use less water for each cleaning cycle than twist or push taps (Figure 4). In a domestic context in UK/Ireland water has typically been supplied unmetered (flat rate annual charging), so there has been little concern with the efficiency of home toilet facilities, but clearly for large institutions with multiple bathrooms in intensive use, the charges for water usage are a variable cost that needs to be controlled and ideally reduced; this doubly so for the costly provision of heated water for hand washing.

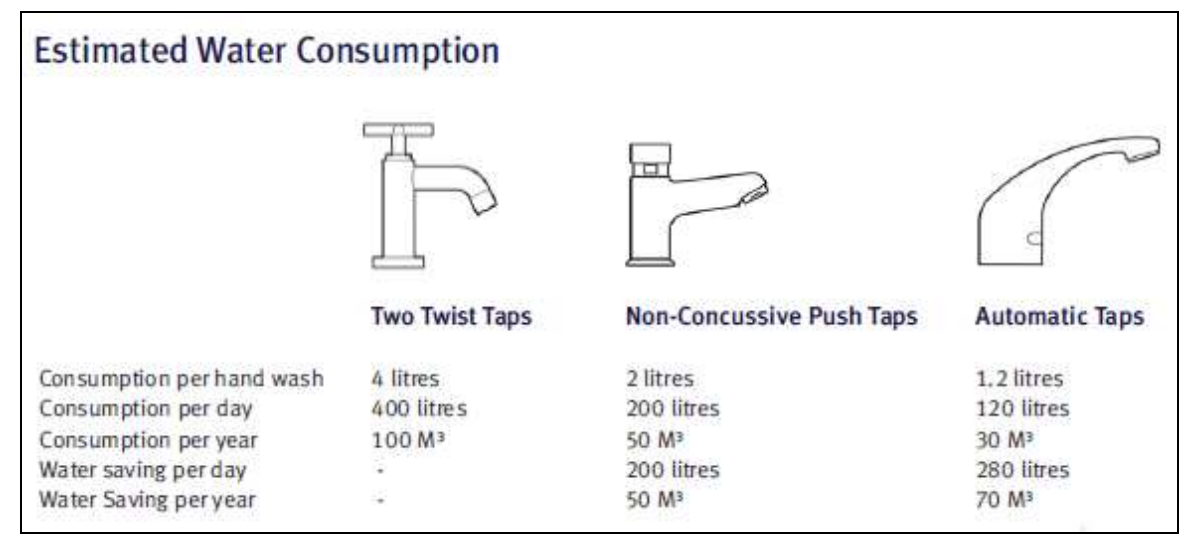

Figure 4. Part of the marketing literature for automatic taps is a comparative chart for potential water savings from updating to no-touch taps over conventional faucets. (Source: Dart Valley Systems Ltd, <www.dartvalley.co.uk>, 2010.)

A contemporary subset of the efficiency discourse in promoting technologies is the appeal to sustainability of operations in addition to cost savings: "saving water is good 
for the environment" (Figure 3). Being seen to be 'sustainable' has become a key benchmark for many institutions and corporations, speaking to notions of morality and care for the community. Saving water is one of leading mantras in sustainability, given its iconic status as essential element for living and its material scarcity in many parts of the world. The automation of toilets can therefore be justified as a sustainable 'solution', especially when it connects so well to economic rationality.

For building owners and those responsible managing of shared public toilets the appeal to reliability is another powerful discourse. For any technology subject to intensive usage, it must work as intended day in, day out, with minimal care and maintenance. Shared public toilets have long been notorious as sites for malicious usage and bathroom fixtures must be designed in consequence, with marketing claims such as "superior heavy duty construction offers resistance to vandalism and misuse" (Figure 3). Here, the benefits notionally flowing out of new toilet technologies are not around touch-free automation per se but, according to British Toilet Association's 'best practice guide' (BTA 2010, 30): “A non-touch system with a concealed cistern provides less opportunity to vandalise the unit and is more hygienic." In a larger sense, reliability is also bound up with issues of installation and maintenance that are stressed as being 'easy' and 'problem-free' (Figure 3). Such a prosaic appeal should not be dismissed. Given that some touch-free technologies are still relatively new, the stress is how manufacturers can offer 'complete solutions' and ones that can be straightforwardly retrofitted into existing toilet spaces.

Another discourse used to promote toilet technologies is control over the space and new means of knowing for building services managers tied to issues of enhancing safety/security, which has become a fundamental promotional discourse in a risk conscious world. Control is coupled with configurability that promises greater flexibility for cleaning operations. The programmability through software means it is possible to change parameters to suit local contexts rather than rely on factory defaults often locked into an electronic system. For example, in Figure 3 the advert lists the feature of “Additional control systems allow custom run-times", indicating that manufacturers believe some customers will pay more for perceived greater degree of control. Managers can also be offered options to override and lock-out water supply to forestall abuse and resist vandalism. 
Other promotional narratives for 'touch-free' technologies, while aimed at facilities managers, stress the advantages to patrons, detailing how new toilet fixtures work better than existing ones. Discourses around new technologies often claim enhanced convenience in tackling existing tasks or wholly new kinds of tasks, elemental to claims of being modern. Such promises of convenience are central to consumer-oriented societies, with each new round of technology assertively claiming to be easier to use than the preceding ones, reducing the time burden to complete mundane tasks and cognitive effort to sustain everyday living. Convenience is often stressed for target groups of people who might have suffered inconvenience with the design or operation of existing technologies. As Figure 3 notes: "Easy to use - ideal for disabled and elderly". Other manufacturers stress the compliance with disability equality legislation for their toilet automatic products. This kind of claim emphasising the positive attributions of being 'touch-free' however presumes that 'elderly' or 'disabled' are meaningful categories of users, all sharing the same bodily (in)capacities. Research has disputed this, showing how some new automation technologies can make toileting harder in some contexts for some users (cf. Bichard et al. 2006, 2008).

In many respects these discourses represent a continuation of established modernist narrative that technologies can make life better, updated in contemporary contexts in terms of 'digital dreams' and the bold claims for so-called 'smart systems'. Bathrooms, with their specialized equipment and fittings, have long been sold as sites of modernity and a place for displaying ones tastes and distinctions in terms of consumption. Modern technologies are promoted through their capacities to change everyday life for the better by ameliorating its supposed constraints, such as taming nature, removing physical drudgery, enhancing enjoyment, adding luxury. As such, the technologies of the toilet have been, and remain, a way to project social status, with the focus on design quality, minimal ornamentation or moving parts, conducive to an historical aesthetics of modernity (cf. Gürel 2008). The main role of technologies here is to hide the messy mechanical control and necessary hydraulic work being conducted, with clean lines that conceal operations and subliminally demonstrate mastery over nature, bringing hygienic orderliness to the world (at least within the confines of the bathroom space). Such designs mean there are also smooth surfaces and fewer visible mechanical elements to harbour germs and disgusting deposits. 


\section{Does touch-free technology make a difference?}

"[h]owever natural automated fixtures might seem to engineers, they are all not natural and can even seem alienating to lay users" (Braverman 2010, 15)

A key aim for this chapter was to begin to understand how far digital technology can transform everyday practices of touch. We are concerned to understand how distinct 'smart' technologies, in the form of sensors and software automation, utilises its technicity to transduce the space of shared public toilets differently; how it can make a real difference to how people go to the toilet, and how they feel about the activity in shared public spaces. Sensor technologies for touch-free activation are certainly becoming more prevalent in many toilet spaces, and are clearly being marketed as powerful tools in modifying the practices of touching. However it is unclear how far touch-free technologies really work in terms of reducing the sense of disgust from direct contact with 'dirty' surfaces shared with strangers, thus making this public space more tolerably habitable?

More conceptually we hope our focus can at least start to provide ways to think about how the technicity of code works in automatically affecting spatiality, for example in the ongoing cultural categorisation of space as 'dirty / clean', 'safe / risky'. Can code itself automate the ordering of the world by ensuring humans keep 'matter-in-place'? The unacknowledged myth being worked towards is that touch-free sensors and the secondary agency of software can bring into being fully automatic space, such as public toilets that would offer such highly ordered function that surfaces would never become categorised 'dirty' because 'matter' would never be left 'out of place'. Bathrooms as code/space (cf. Kitchin and Dodge 2011) would thus remake human toileting into a wholly civilised and virtuous practice, preventing it from slipping into an uncivilised and immorality. Code would provide the ultimate triumph of modernism over nature by completely disconnecting human control over space from the intimate touch of our own corporeality. All embracing software automation also offers up the means to avoid the disgusting animality of others that we are forced to encounter in shared public toilets.

However, in spite of the hype and some potential benefits from touch-free technologies for enhanced convenience and hygiene, their real world implementation is always 
imperfect. Given that touch-free technologies in shared bathrooms are about enhancing the conventionalised boundaries between 'clean' and 'dirty' in toileting practices by progressively removing the need to touch surfaces, the incomplete and inconsistent way they are deployed means they can only fail in this task. The incomplete deployment of sensors and software across the sequence of activities (including opening doors) means that toileting as a whole can never be rendered fully touch-free and the bathroom fails to become a completely automated code/space. This incompleteness also undermines much, if not all, of the validity of hygiene and sanitation discourses used in the marketing of touch-free technologies. If software automation in shared toilet spaces is genuinely about improving cleanliness then comprehensive, 'end-to-end', implementation of touchfree interaction is needed to insure (near) zero means of germ cross-contamination. Failure at any of the key points in toileting activity by an unavoidable direct touch of a potentially contaminating control surface (such as a door lock) means the complete hygiene chain is broken, that the body is no longer safely in the 'clean' category. The results of incomplete and haphazard provision touch-free technologies in public toilets minimises their value for contaminant control. (Notwithstanding the fact that in reality some people do not wash their hands regardless of the technological solutions on offer and normative cultural requirements.) Moreover, there is evident inconsistency between public toilets provision, across a single institution or even within the same buildings (some have no-touch taps but nothing else, others only provide auto flushing of urinals or hand dryers).

Touch-free technology is almost always implemented partially, and also partial in different ways, which can make for user frustration as one is uncertain about how bits of an unfamiliar bathroom are meant to work: 'so where do I wave my hands to get some soap?'. The current lack of standardisation of implementation of touch-free sensors can also cause distress for those who struggle with embodied practices in public toilets (Bichard et al 2008) and can be subtly disabling for some people. Indeed, simpler mechanical bathroom fixtures are better for some users and the prosaic operation of a tap can be made more problematic with the addition of touch-free technology because the position of the sensor 'eye' is inconsistent across installations, the speed of response and the duration of water flow varies - this may cause frustration in a normal person, but may prevent a less able person to wash their hands successfully. Another example is how automated air fresheners dispense chemicals that are harmful to some, aggravating 
asthma symptoms, and then they are only masking offensive smells to give the impression of hygiene, rather than actually purifying the air to remove dust and bacteria .

The partiality of toilet code/spaces is indicative, we would argue, of the modernist hubris that underpins so many 'smart' homes discourses and some of the alluring promise of pervasive computing (Dodge and Kitchin 2009). Such discourses represent a desire for 'tidy space', an excessive orderliness and scientifically rationalised behaviour. This can be read as a "modern fetish for the appearance of hygiene" which:

"does not assure cleanliness it promises. Instead, it merely obscures dirt; indeed, all natural (and finally, historical) processes. Tidiness in fact is only interested in obscuring all traces of history, of process, of past users, of the conditions of manufacture (the high high-gloss)... The tidy moment does not recognise process, and so resists deterioration, disease, aging, putrefaction." (Michaels 1990, quoted in Barcan 2005, 9)

The danger is then that toileting is set to become an over-determined activity. Attempting to make avowedly simple activities touch-free with digital sensors and software algorithms is simply unnecessary it could be argued, and an excess of automation in the bathroom could be critiqued as an example of disciplining the body through 'technological paternalism' (Spiekermann and Pallas 2006). In step with other discourses extolling the virtues of onrushing 'intelligent environments' bodies should no longer be anonymous entities, but instead become identifiable in code as known people and have their routine activities recorded. Perhaps a few people will actually volunteer to have sousveillance built into the toilet bowl, having bathroom sensors and software monitor their every motion, as part of a health obsessed and bodily performance auditing culture. Yet would most people actually want automated, 'intelligent' toilets that identifying them and logging their 'outputs'? (cf. Braverman 2010). The bathroom and toilet cubicles are one of the few remaining private spaces in modern living (e.g. in many public buildings they are the only space without routine CCTV coverage), but they seem to have the potential to become a new frontier of software surveillance.

More broadly the task of mapping out the places we can touch, the places where we avoid or are compelled to touch, is an interesting challenge for geographers, and we believe this focus on public bathroom spaces and toileting practices is worth exploring 
further. The arguments presented are only a preliminary consideration of the role of touch-free sensor technologies and software automation to remake the space of toilets as 'clean' code/space by reconfiguring embodied toileting practices. The analysis needs to be extended by drawing upon a wider range of empirics from auditing different shared public toilets (in different contexts, ages, and levels of usage) and from a deeper level of evidence gained by more ethnographic observations of toileting practices and the impacts of technologies on underlying meanings and motivations of performances. Clearly this kind of study of personal practices would require sensitivity given the private nature of toileting and ethical considerations regarding research in shared public space (cf. Barcan 2005, Molotch and Noren 2010).

We believe such studies would be worthwhile to advance the understanding of ways various digital technologies work to mediate direct touch in everyday situations and as such it could contribute to wider understanding in at least four areas of geographical scholarship. Firstly, in terms of affective work looking at emotional and sensual geographies highlighting how the tactile nature of spatial experiences are changed by sensors. Secondly, it could contribute useful empirical findings using ideas around nonrepresentative practices in public environments, particularly in relation to technological control over human bodies and how this is often deflected or sometimes resisted. Using ontogenic notions one could see how toilets come into being as spaces of techno-social practice. Thirdly, such work can advance an understanding of the spatial and social implications of pervasive computing by mapping out how and why the 'automatic production of space' is likely to remain partial, using toilets which are vital but overlooked spaces. The problems of putting code to work in mundane places like public toilets, and the fact that it is so incomplete and inconsistent, actually makes it a fascinating site for doing software studies (cf. Kitchin and Dodge 2011). Lastly, this work speaks directly to the changing the nature of what it means to human. As such it could contribute to debates on post-humanism in which the technologies of touch change embodied relationships with the material landscape. Is automation as code/space always going to be imperfect and the fetishistic desire for fully touch-free interaction will never be realised? And even if code/spaces built with touch-free sensors and software automation were realisable, would people want them given the deeper psychological impacts that might result from such corporeal disconnection. Touch-free technologies, therefore, are part of what Robert Macfarlane $(2007,203)$ laments as the "retreat from 
the real.... a prising away of life from place, an abstraction of experience into different kinds of touchlessness". Software may be able to bring more touch-free spaces into, but would we want fully to live a touch-less existence?

\section{References}

Barcan, R. 2005. Dirty spaces: Communication and contamination in men's public Toilets. Journal of International Women's Studies, 6(2), 7-23.

Bichard, J., Hanson, J. and Greed, C. 2006. Away from home (public) toilet design: identifying user wants, needs and aspirations, in Designing Accessible Technology, edited by P.J. Clarkson, P.M. Langdon and P. Robinson. London: Springer.

Bichard, J., Hanson, J. and Greed, C. 2008. Please wash your hands. Senses and Society, 3(1), 79-84.

Braverman, I. 2010. Governing with clean hands: Automated public toilets and sanitary surveillance. Surveillance and Society, 8(1), 1-27.

BTA. 2010. Publicly Available Toilets: Problem Reduction Guide, Third Edition. The British Toilet Association and Hertfordshire Constabulary Crime Prevention Design Service, <www.britloos.co.uk>.

Cresswell, T. 1996. In Place/Out of Place: Geography, Ideology, Transgression. Minneapolis, MN: University of Minnesota Press.

Dixon, D.P. and Straughan, E.R, 2010. Geographies of touch/touched by geography. Geography Compass, 4(5), 449-59.

Dodge, M. and Kitchin, R. 2009. Software, objects, and home space. Environment and Planning A, 41(6), 1344-65.

Douglas, M. 1966. Purity and Danger. London: Routledge.

George, R. 2008. The Big Necessity. London: Portobello Books.

Graham, S. 2009 Disrupted Cities: When Infrastructure Fails. London: Routledge.

Greed, C. 2006. The role of the public toilet: pathogen transmitter or health facilitator? Building Services Engineering Research and Technology, 27(2), 127-39.

Gürel, M.O. 2008. Bathroom as a modern space. The Journal of Architecture, 17(3), 21533.

Hetherington, K. 2003. Spatial textures: place, touch and praesentia. Environment and Planning A, 35(11), 1933-44. 
Jewitt, S. 2011. Geographies of shit: Spatial and temporal variations in attitudes towards human waste. Progress in Human Geography, 35(5), 608-26.

Kitchin, R. and Dodge, M. 2011. Code/Space: Software and Everyday Life. Cambridge, MA: MIT Press.

Mackenzie, A. 2006. Cutting Code: Software and Sociality. New York: Peter Lang.

Macfarlane, R. 2007. The Wild Places. London: Granta.

Molotch, H. 2008. Peeing in public. Contexts, 7(2), 60-63.

Molotch, H. and Noren, L. 2010. Toilet: Public Restrooms and Politics of Sharing. New York: New York University Press.

Paterson, M. 2007. The Senses of Touch: Haptics, Affects and Technologies. Oxford: Berg.

Spiekermann, S. and Pallas, F. 2006. Technology paternalism - wider implications of ubiquitous computing. Poiesis \& Praxis: International Journal of Ethics of Science and Technology Assessment, 4(1), 6-18.

Thrift, N. and French, S. 2002. The automatic production of space. Transactions of the Institute of British Geographers, 27, 309-35. 
Table 1: Summary of the range of digital technologies available for installation in shared public toilets.

\begin{tabular}{|c|c|c|c|}
\hline Activity & Technology function & Automation / Sensing & Replaces / Augments \\
\hline \multirow[t]{4}{*}{ User access } & Entrance/exit doors & $\begin{array}{l}\text { Automatic opening, PIR sensor detects approach } \\
\text { of human body }\end{array}$ & $\begin{array}{l}\text { Manual opening with hand; powered- } \\
\text { assistance door activated by button press }\end{array}$ \\
\hline & WC cubicle door opening/locking & None & $\begin{array}{l}\text { Still largely manual opening with hands, } \\
\text { mechanical lock }\end{array}$ \\
\hline & Access control, fee payment & $\begin{array}{l}\text { Electronic opening barriers, digital sensor count } \\
\text { people and checks money, software logging of } \\
\text { fees and usage statistics }\end{array}$ & Manual turnstile with mechanical counter \\
\hline & Lighting & $\begin{array}{l}\text { Timed; automated according to daylight; } \\
\text { activation in response to human presence via PIR } \\
\text { sensor }\end{array}$ & $\begin{array}{l}\text { Always on; electro-mechanical timing; } \\
\text { manual activation by light switches }\end{array}$ \\
\hline \multirow[t]{7}{*}{ Toileting } & Urinal flushing & $\begin{array}{l}\text { Programmable settings for variable flush } \\
\text { sequences; PIR sensor for flush after use; } \\
\text { monitors usage, reports status }\end{array}$ & $\begin{array}{l}\text { Manual activation; electro-mechanical timed } \\
\text { flushing }\end{array}$ \\
\hline & WC seat cleaning / cover & Activates after flush & $\begin{array}{l}\text { Manual cleaning; button push for } \\
\text { mechanical dispensing of new cover }\end{array}$ \\
\hline & WC paper dispensing & $\begin{array}{l}\text { PIR sensor for dispensing of measured amount; } \\
\text { potential to monitor usage, reports status }\end{array}$ & Manual dispensing with hand \\
\hline & WC flushing & $\begin{array}{l}\text { PIR sensor for 'wave' activation and also 'walk } \\
\text { away' activation; monitors usage, reports status }\end{array}$ & Manual activation by hand on lever / button \\
\hline & Sanitary product bin? & None? & Manual disposal into sanpro bins \\
\hline & [More in female WC?] & $? ?$ & \\
\hline & $\begin{array}{l}\text { Accessible WC - Distress alarm / call } \\
\text { system } \\
\text { [Accessible WC - anything else?] }\end{array}$ & $\begin{array}{l}\text { Digital call circuit routed to control centre; logs } \\
\text { usage }\end{array}$ & $\begin{array}{l}\text { Calling for help; electrical alarm trigger and } \\
\text { local bell / flashing light to signal attendant }\end{array}$ \\
\hline \multirow[t]{3}{*}{$\begin{array}{l}\text { Hand } \\
\text { washing }\end{array}$} & Water dispensing & $\begin{array}{l}\text { PIR sensor for touch-free activation; automatic } \\
\text { cleaning cycles; monitors use and failsafe cut-off }\end{array}$ & $\begin{array}{l}\text { Manual activation by hand using twist or } \\
\text { percussion push taps }\end{array}$ \\
\hline & Soap dispensing & PIR sensor for touch-free activation & $\begin{array}{l}\text { Soap blocks; manual push button dispensing } \\
\text { of liquid soap }\end{array}$ \\
\hline & Hand drying - air dryers & PIR sensor for touch-free activation; monitors & Paper towels / roller linen towel; manual \\
\hline
\end{tabular}


Hand drying - paper towels

Environmental Flushing (complete system for cleaners) and hygiene

control

Heating, AC, ventilation

Odour control systems (Ozone generator, perfume spray)

Air sanitizer ??

CCTV

Metering of usage

Alarms (smoke, fire, flooding, burglary)

Miscellaneous Cleaner time \& attendance system

Vending machines? usage

PIR sensor for touch-free dispensing of measured amount; monitors usage

Simultaneous flushing cycle of all units, super flush for deep hygiene clean; monitors use and failsafe cut-off

Programmable and flexible settings. PIR sensors for activation only when space is in use; reports status and logs operation

Programmable and flexible settings. PIR sensors for activation only when space is in use; reports status

??

Networked, digital system to remote centralised control; logging; potential for algorithmic detection of unusual behaviours

Digital meters, logging status, remote reading, detecting and reporting faults

Integrated with BMS, networked for remote monitoring, logging status, reporting failures

RFID identification, reports failure, logs status

Monitors stock level and networked to report status and faults activation of dryer by push button

Manual dispensing by hand touch

Manual flushing of units separately

Manual controls; electronic timings and thermostatic sensors

Electromechanical operation, electronic timing

Presence of human attendant onsite; analogue television monitored locally

Mechanical meters, manual reading

Electromechanical alarm linked to bells and lights; electronic alarm operating locally

Paper based recording; electronic "punch cards'

Periodic restocking 
